\title{
Underground coal gasification technology impact on coal reserves in Colombia
}

\author{
Impacto de la tecnología de gasificación bajo tierra sobre las \\ reservas de carbón en Colombia
}

\begin{abstract}
In situ coal gasification technology (Underground Coal Gasification-UCG-) is an alternative to the traditional exploitation, due to it allows to reach the today's inaccessible coal reserves' recovery, to conventional mining technologies. In this article I answer the question on how the today's reserves available volume, can be increased, given the possibility to exploit further and better the same resources. Mining is an important wealth resource in Colombia as a contributor to the national GDP. According with the Energy Ministry (Ministerio de Minas y Energía) [1] mining has been around 5\% of total GDP in the last years. This is a significant fact due to the existence of a considerable volume of reserves not accounted for (proved reserves at year 2010 were 6.700 million of tons. Source: INGEOMINAS and UPME), and the coal future role's prospect, in the world energy production.
\end{abstract}

Keywords: Coal, Exhaustible Resources and Development, Simulation, Energy, UCG Technology.

\section{Resumen}

La tecnología de gasificación in situ (Gasificación de Carbón Subterránea-UCG, en inglés-) brinda la alternativa de consumir carbón de forma diferente a la tradicional y permite una explotación de reservas inalcanzables con tecnologías de minería convencional. Este artículo responde la pregunta sobre cómo aumentan las reservas de carbón disponibles para explotar, y su impacto en el beneficio del país. La minería es un importante recurso de riqueza para Colombia, contribuye con cerca del 5\% del PIB. Lo significativo de este hecho se debe a la existencia de un considerable volumen de reservas (6.700 millones de toneladas) y al futuro rol del carbón en la producción mundial de energía.

Palabras clave: Carbón, Recursos exhaustibles y desarrollo, Energía, Tecnología de UCG.

* Ph.D. Management Student (Finance), Universidad de Los Andes. Assistant Professor at Universidad Pedagógica y Tecnológica de Colombia(Colombia).john.rosso@uptc.edu.co 


\section{INTRODUCTION}

According to the World Coal Institute -WCI-, coal is one of the world most important energy resources. Near to $40 \%$ of world's energy is produced by using coal [2]. The coal consumption became three fold during the last 30 years (Fig. 1). Together over $73 \%$ of the world coal production is consumed by countries like China, India, United States, Russia and Germany [3]. Colombia's consumption is only $0.1 \%$ of the total, in spite of being one of the world biggest coal producers [4].

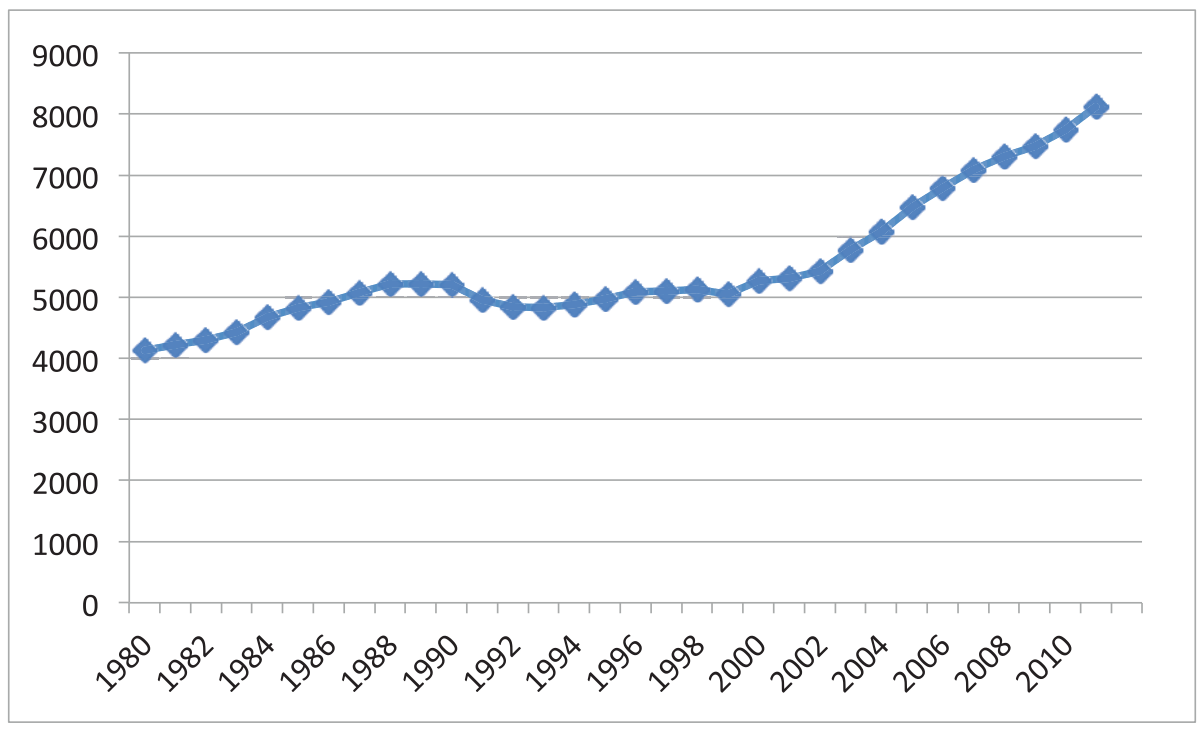

Fig. 1. World coal consumption by year (millions of Short Tons)

Source: Data from United States Energy Information Administration [5]. Own elaboration

The latest new coal uses and the technologies development, such as coal liquefaction or gasification in situ, suggest a high future industrial demand. In particular, the UCG is a technology that has a clear impaction the exploitable reserves' volume. This implies that it is necessary to estimate the new coal national reserves inventory, given the possibility to implement the UCG technology in Colombia.

Recent studies show that the UCG projects around the world have not had any development in Latin America [6] in spite of being a potential development for the region. According to Friedmann et al. [3], Latin America could be considered one of the regions with highly prospective for future UCG projects development.

Current development of UCG has shown an advanced efficiency, making this process the cheapest, as it requires lower capital and operating costs [7]. Therefore it is possible to consider some UCG potential projects in Colombia, in order to improve the national coal resources amount and the energy production efficiency. Since UCG allows to mine the coal resources that today are impossible to extract by traditional mining [69], the question is: ¿How much will change the efficiency and the proved coal reserves' amount in Colombia, under the UCG project scenario?

\section{Underground CoAL Gasification}

Underground Coal Gasification (UCG) or in situ gasification, is a process that converts coal into a synthetic gas, called syngas (this term is used to summarize the mix of gases obtained by the process. The produced gases are primarily $\mathrm{H}_{2}$, $\mathrm{CO}, \mathrm{CH}_{4}$, and $\mathrm{CO}_{2}$ ) [7]. This procedure differs from the surface coal gasification, due that with 
the UCG, the un-mined coal seams, are injected with sufficient oxygen, for a complete combustion underground [10].

Since the UCG wells have permeable walls, as water is injected at hydrostatic pressure, the controlled pyrolysis and the evaporation process' create the unburnt gas. This syngas is extracted through the wells drilled down, into the coal seam. The gas is collected and transported into the surface facilities, for further use in energy production or others (see Fig. 2).

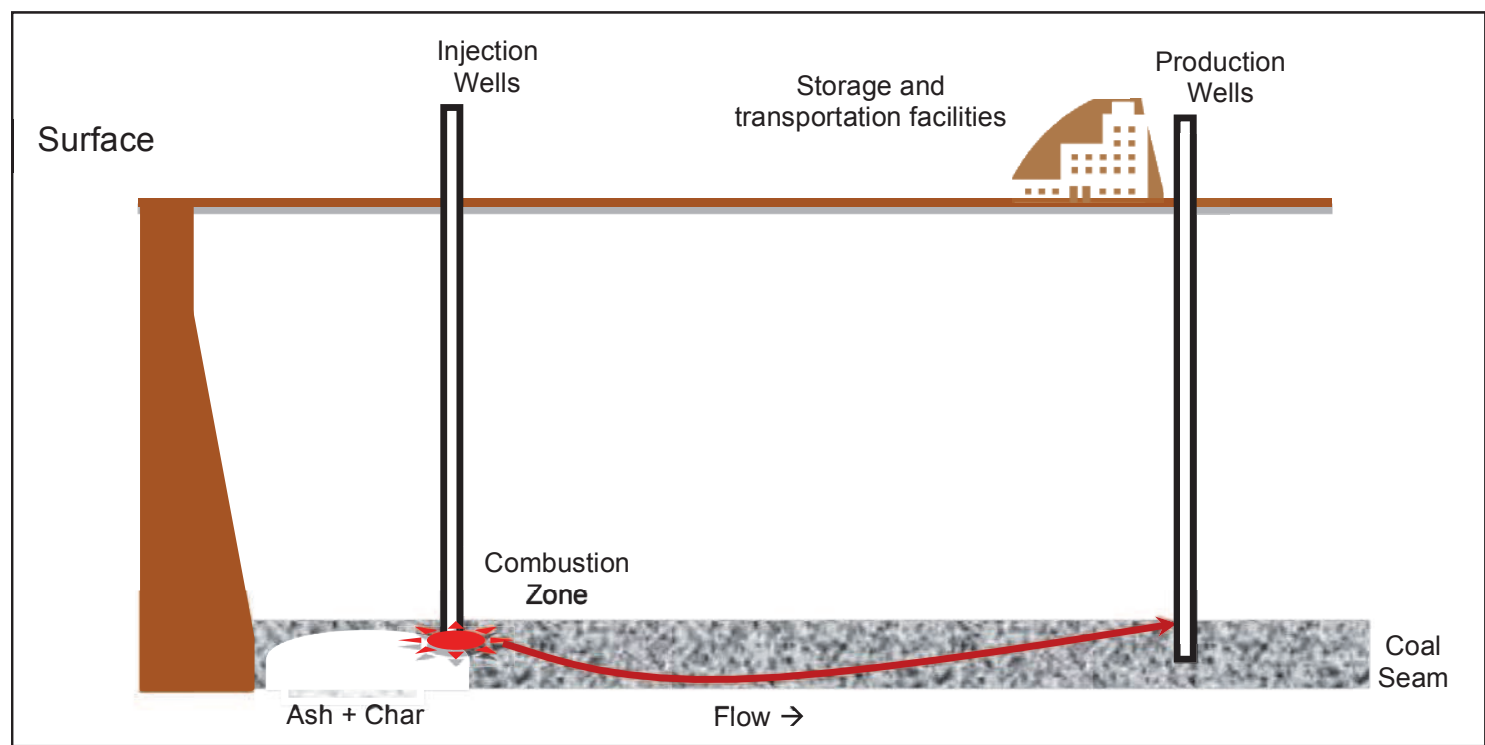

Fig. 2. UCG process.

Source: Own elaboration. Based on [11]

The gasification pressure is not an independent design variable, in the UCG process. Instead, it is a hydrostatic pressure's function, which increases with the coal seam's depth. The gasification rate growths with the increasing coal depth, due to an upsurge in the gasification pressure [10]. This is an important input, for the UCG decision time, in the coal bed selection.

There are many designs that have proven to successfully operate an UCG project, depending on its characteristics (mainly geological). But as it has been suggested, the project success, lies on the coal seam permeability to create gases [6], [10].

\section{A. Current Status}

Klimenko [9] pointed out that there are more than 30 new trials being conducted in Australia, China, India, South Africa, New Zealand, Canada, and the U.S. The R\&D, Research and Development, in UCG has provided new tools for this technology's better understanding. The knowledge concerning the well design, and the gas recovery, between other variables, have given a renewed interest in UCG projects around the world.

One the UCG technology' pioneers, was the USSR where the research allowed the plant's operations since 1930's. According to Shafirovich and Varma [7] the Former Soviet Union (FSU) has been one of the coal gas bigger producers, by using UCG technology. At that time, there were 15 Mt of coal gasified underground, in FSU, while just $50 \mathrm{Kt}$ in USA [7].

The FSU has promoted important advances in the technology development. The coal seam's hydraulic fracturing by pressurized air or water, has led the wells' linkage between injection and 
production; the coal seam thickness' learning; the mathematical and simulation models on the chemical reactions, have been some of the most important results [7]. Also in the US there have been improvements, since the 1970's when the UCG projects development started. The mathematic models to understand the cavity growth, the combustion reactions and the carbon management during UCG, are some of them.

In contrast, in Europe the main experiences were not successful in Spain, France or Belgium, but they shed valuable learning to the UCG technology development. In France, the first experience, just starting the 80's, reported a problem with the linkage between the wells and the coal ignition. A later test in 1983, failed on the same technical issue [7]. In the middle eighties in Belgium there was a project, that also failed in the linkage between wells. And in Spain, there was a problem with the temperature and pressure measurement, which led to an explosion due to the Methane accumulation. Then, the experiment was closed [7].

China is considered to have the world most important UCG programs; they have obtained a great number of patents during the last years. On the other hand, Australia has developed one of the most efficient UCG projects, from the coal resources recovery's point of view $(95 \%)$ and the energy recovery $(75 \%)$ [7].

\section{B. Criteria for an UCG project selection}

As has been pointed out above, one of the UCG project key factors, is the location selection. The main elements considered for this selection [12] are:

- The Coal rank. It is one of the most important selectors, because it directly determines the gas production quality. Moreover, it facilitates the linkage between wells [7], [12].
- The Composition. The features such as the ash, sulfur and moisture's amount, also affect the gas quality, but they can also inhibit the UCG process [12].

- The Porosity and permeability. Variables necessary to improve the gas flow [13].

- The Partings. It refers to the limestone, clay layers, shale, or other rocks that locally separate the coal, into multiple layers within a given seam [12].

- The Depth and aquifers, the depth and subsidence. It refers to the geologic layers' structural integrity, above the coal seam.

- Hydrology. The water sources are useful to reach the gasification reaction in the process.

- Coal seam thickness and angle. (dip)

- Coal reserves and accessibility.

\section{Criticism}

It has been recognized that the UCG technology presents technical, environmental and economic advantages, against the traditional mining or the alternative technologies like the surface gasification. However, as the advantages are numerous, it still faces some challenges, which imposes some restrictions, for its implementation.

From the environmental benefits point of view, the UCG technology allows to control some pollutant gases' emission and it is an alternative for carbon storage and sequestration. However, it can bring negative consequences in the groundwater contamination, if the effects are not correctly mitigated [6], [8], [10].

Compared with the other coal uses, like the surface gasification or the energy production in thermal plants, the UCG considerably reduces the environmental pollution, due to the gases or ashes on the air's easier control. 
Other risks associated to UCG are, the subsidence where the coal seams are shallow, the $\mathrm{CO}_{2}$ leakage when the carbon capture and storage (Carbon sequestration, also known as carbon capture and storage (CCS), is a technique to capture $\mathrm{CO}_{2}$ at coal-fired power plants, transporting the gas, and storing it instead of letting it enter the atmosphere) technology is linked to UCG [14]. It is important to have into account, the legal restrictions depending on the local authorities, related to the environmental aspects for the site selection.

Other technical challenges concerning the gas recuperation by using the coal seam hydraulic fracture, have been mentioned above.

But, still there are big engineering difficulties, since the process cannot be easily controlled, like a surface gasification process. For example, it is not possible to control the pyrolysis direction, the cavity expansion and growth, and the response to the injection composition [6] due to the water and air influx, it is difficult to reach the ideal temperature for UCG [8].

Regarding the economic perspective, it has been highlighted that by the UCG, the un-minable coal resources could be gasified, since the drilling is able to reach deeper seams, than those exploited by traditional mining. Fiedmann et al. [6] have pointed out that this requires four conditions: 1) Strong technical knowledge (Chemistry, Geosciences); 2) Commercial facilities; 3) A high level environmental protection, and, 4) Some active carbon strategies in the country (particularly concerning CCS). On the other hand Bell and Towler [10] consider, that it is necessary to leave an amount of coal walls unburned, to avoid water contamination, reducing the recoverable coal quantity.

\section{Consequences OF DEEPER COAL EXPLOITATION}

The recovered gases' final disposition is an important input, to assess any UCG project's viability. If the recovered gas has to be transported long distances, the increasing transport cost, decreases the economic advantage that the project could have. Surface facilities are important part of an UCG project's viability.

This work main hypothesis is that the UCG allows additional resources exploitation, that are impossible to extract by traditional mining. Given the depth recommended for this kind of projects, it is quite important to understand the deeper coal resources exploitation's consequences, than those exploited by traditional mining.

Heriawanand Koike [15] demonstrated that the coal seams geological and chemical characteristics, are heterogeneous respect to their spatial location, by using different multivariate and univariate techniques. Álvarez-Fernández et al. [16] have studied the local variation influence, in the coal seam's thickness, in a practical case of surrounding stresses, in the underground mining. With these studies it has been found that the depth changes the coal seam characteristics. This phenomenon is known as a Hilt's law (the coalification degree's dependence on depth) and it is considered as a substantial and longacknowledged rule [17].

For example, in a particular study, Sivek et al. [18] found that bituminous coals' moisture content, varies with the depth (a case study from the Czech part of the Upper Silesian Coal Basin). Authors found that the trends in the volatile matter moisture- and the ash-free depend on the "stratigraphic depth". The general trend of the decreasing volatile matter contents with depth, was undoubtedly confirmed. Coal seams show less volatile matter contents, than their overlying seams [17].

The depth can reduce the coal quality. The high pressures and temperatures ranging meta genesis process to metamorphism, implies that the organic matter is associated, in the form of graphite and diamond doids, in more extreme 
cases, with a lack of commercial value. However for this to happen, it requires high temperatures around $200{ }^{\circ} \mathrm{C}$ (sometimes it reaches $250{ }^{\circ} \mathrm{C}$ ); a typical watershed geothermal gradient is 20 to 30 ${ }^{\circ} \mathrm{C}$ per kilometer of depth. Following this idea, it is found a coal deteriorated from $6 \mathrm{~km}$ to $8 \mathrm{~km}$, hence economic and technical mines should not be set too deep.

Thus at a depth greater than $600 \mathrm{~m}$ to $1200 \mathrm{~m}$, for example, there is a lower coal thickness (the author studied the US Contour maps of coal resources by State, and they can be obtained upon request), but they are offset by less moisture and therefore a much higher calorific value coals, type "anthracite"; this contrasts with the ash content which tends to be greater [17].To explain the ash increase, if the coal seam depth becomes irregular, it could contain some larger particles of inorganic materials that prevent the coal quality formation, due to the anisotropy. However each basin, has its own individual characteristics and it just can be detailed by the drill findings.

In general, at greater depths (more than $600 \mathrm{~m}$ ) one should find excellent quality coals, although less thick, as long as the mantle is isotropic, which depends on the shell and its features. According to Heriawan and Koike [15] the uncertainty term in the coal reserves assessment, is related to the lack of a thickness variability measure. In any case, this finding immediately leads to decide what coal layer must be removed, which makes it more difficult for the technologies to be implemented where the open pit is almost mandatory.

\section{Coal Reserves-Resources DEFINITIONS UNDER UCG}

The coal reserves definitions accepted in Colombia, was published by the Mining and Energy Ministry in 1995 [19], and remains unmodified until today. There are five categories for classifying the resources and reserves, depending from the distance, by which information points are separated:

a. Measured: Separated by $500 \mathrm{~m}$ of distance from each other.

b. Indicated: Separated from $500 \mathrm{~m}$ to $1500 \mathrm{~m}$ of distance from each other.

c. Inferred: Separated from $1500 \mathrm{~m}$ to $4500 \mathrm{~m}$ of distance from each other.

d. Hypothetic: Separated by more than $4500 \mathrm{~m}$ of distance from each other

e. Speculative: There are no information points or they are separated by extremely great distances.

The final classification is determined by a standard table, in which are defined, the called "threshold values", over some variables like: Coal quality, seam' slope, distance between the measuring points, sterile intercalations, coal seams thickness and depth. Then, these definitions depend on the certainty degree to make the estimations, because each category is related to a reasonable certainty test.

Measured: Separated by $500 \mathrm{~m}$ of distance from each other.

Indicated: Separated from $500 \mathrm{~m}$ to $1500 \mathrm{~m}$ of distance from each other.

Inferred: Separated from $1500 \mathrm{~m}$ to $4500 \mathrm{~m}$ of distance from each other.

Hypothetic: Separated by more than $4500 \mathrm{~m}$ of distance from each other.

Speculative: There are no information points or they are separated by extremely great distances.

However, concerning the coal definitions there are ambiguities recognized by different authors [20]. For example, according to Alpern and Lemos [21], in the ISO 14180 standard, the definitions is: "A coal seam stratum or sequence of strata 
composed of coal as a significant component and significantly different in lithology to the strata above and below it. Note: It is laterally persistent over a significant area and it will be of sufficient thickness and persistence to warrant mapping or description as an individual unit". At the same time, Alpern and Lemos consider that the definition is very imprecise in the depth, thickness and lithology's terms. On the other hand Schuenemeyer and Power [22] proposed a method to estimate the uncertainty for coal resource assessment; also, Bardossy et al. [23] proposed their own resource estimation method.

Some aspects that impact UCG technology, are the coal seams thickness and depth definitions. There are high differences between countries. For example, in Ukraine it has been classified as proven reserves, the coal resources until $1800 \mathrm{~m}$ depth [21], while in Colombia is just 1200m [19].

Luna et al. [24] made an extensive study on the coal resources, reserves and quality in Colombia. They divided their work by the different coal zones recognized in Colombia, in order to estimate the reserves and to establish the coal general features in such regions. They present the proven reserves' amount and made an inference on the hypothetic reserves in the country. However, in most of the cases it is explicit that their calculations are based on a $300 \mathrm{~m}$ of depth.

The desired geologic and hydrologic characteristics for an UCG project [13], [25] should define a depth between $150 \mathrm{~m}$ and $500 \mathrm{~m}$ for its implementation. In spite of this technical matter, this section purpose is to establish how the UCG technology implementation, which allows exploiting reserves beyond $600 \mathrm{~m}$, could impact the Colombian available reserves amount.

\section{A. Reservoirs calculation}

As Caldwell and Heather [26] pointed out in the USA case, as this classification is completely deterministic, the reserves are imprecise and depend very much on the estimator criteria. In Colombia the current in force coal resources classification, is calculated using the following formula in equation (1):

$$
t=\frac{a \times e \times d}{\cos \phi}
$$

Where:tons, area, weighted average coal thickness, coal density, coal seam slope.

However, the reserves have been defined by estimates in former works, assuming a probabilistic distribution. According to Phillips [27] the earth's crust mineralization follows a continuous distribution, which after simulations is assumed to be lognormal. On the other hand, Caldwell and Heather [26] uses a normal distribution to their reservoir-level probabilistic approach.

However, Bancroft and Hobbs [28] argue that the decision to assume any distributional form, can be made only by the practitioner, who has the problem's more complete appraisal. In general, the geosciences describe the spatial relationship between the geological data taken at the field, by using different statistical techniques.

Here the statistical approach takes some important features, since the samples have their spatial relationships. One of the key factors for the estimations robustness, is to understand the assumptions that define the relationships behind the techniques. The analysis goal, is to estimate some un-sampled location properties by predicting its behavior explained by a sampled one. The main assumption is that the data is stationary, as it is required for an adequate population description by the sample.

Provided that for treating the data, a random function is used, the stationary is defined through the observed random function's first and secondorder moments and the stationary degrees, correspond to the particular moments that remain invariants across a study area [29]. However, 
this assumption is just qualitative, and it never is found perfectly in nature [28], [30].

\section{B. Simulation of coal reserves calculation}

Stochastic simulation has been used to improve the way to calculate reservoirs. It has been useful to model coal resources and to assign and classify reserves [31], [32]. In the same way, sequential Gaussian conditional simulation algorithm, has been used to assess the grade estimates uncertainty and also it illustrates how the simulated models can be incorporated into the mine planning and scheduling [33]; also the conditional simulation [34]. In other cases more complex designs are explored, like the annealing simulation [35] or the forecasting models [36].

In this simulation I used as main parameters for estimating the coal resources, the coal seam areal extent, multiplied by the seam thickness and the in situ density. The areal extent is defined by the areas of influence's Observation Points [37]. The inputs are simulated by using the Crystal Ball ${ }^{\circ}$ program, and the parameters given by the comparison exercise done with some USA states.

Before running the simulation, the coal reserves data for eight USA states, concerning the variance given the sample taken depth, were compared.
The data were compared by the states and the thickness variable. All the data was collected from the public source of the National Coal Resources Data System [38] from USA. They were arbitrarily selected by the different states coal resources quantitative relevance's reported database for each sample.

1) USA coal resources: Since the exercise described above was carried out, in order to get the basic parameters for a simulation, the economic recoverable coal definition, related to the depth, was fixed at $600 \mathrm{~m}$ [19]. It means that each coal resources State's sample, was divided in two subsets, depending on the variable 'Depth'. This variable refers to the drill hole's depth where the sample was taken. Thus, the geostatistics variables were divided in two groups for comparisons.

All runs were carried out by using the Surfer $8^{\circ}$ program. With it was obtained the variogram contour map and a grid geostatistical report, (see Table 1) from the drill holes dataset, by each state's subset. Just for illustration were made all the raw data for thickness histogram, of the coal seam at the drilled holes by state, and then divided for each subset. For all the runs, it was employed the Kriging Variance, by a cross method with a Nugget effect, a Linear component and a Gaussian transformation.

Table 1a

Geostatistic Results

\begin{tabular}{|l|c|c|c|c|c|c|c|c|}
\hline \multicolumn{1}{r|}{ State } & \multicolumn{2}{|c|}{ Colorado } & \multicolumn{2}{c|}{ Iowa } & \multicolumn{2}{c|}{ Kentucky } & \multicolumn{2}{c|}{ North Dakota } \\
\hline Statistic & $\mathrm{d} \leq 600 \mathrm{~m}$ & $\mathrm{~d}>600 \mathrm{~m}$ & $\mathrm{~d} \leq 600 \mathrm{~m}$ & $\mathrm{~d}>600 \mathrm{~m}$ & $\mathrm{~d} \leq 600 \mathrm{~m}$ & $\mathrm{~d}>600 \mathrm{~m}$ & $\mathrm{~d} \leq 600 \mathrm{~m}$ & $\mathrm{~d}>600 \mathrm{~m}$ \\
\hline Min & 5.38 & 1.27 & 6.13 & 8.45 & 4.65 & 8.24 & 9.78 & 10.38 \\
\hline Max & 538.20 & 485.52 & 56.02 & 54.60 & 108.43 & 56.76 & 901.45 & 275.66 \\
\hline Range & 532.82 & 484.25 & 49.89 & 46.15 & 103.78 & 48.52 & 891.67 & 265.28 \\
\hline Mean & 82.58 & 107.73 & 27.36 & 34.88 & 23.48 & 18.11 & 111.01 & 97.20 \\
\hline SD & 48.03 & 56.55 & 6.88 & 9.61 & 17.99 & 8.52 & 48.67 & 51.80 \\
\hline Variance & 2306.46 & 3198.19 & 47.29 & 92.39 & 323.68 & 72.60 & 2368.73 & 2683.56 \\
\hline
\end{tabular}

Source: National Coal Resources Data System. NCRDS. Own elaboration by using Surfer $8^{\circ}$ 
TABLe1B

Geostatistic Results

\begin{tabular}{|l|r|r|r|r|r|r|}
\hline \multicolumn{1}{|c|}{ State } & \multicolumn{2}{|c|}{ Ohio } & \multicolumn{2}{c|}{ Utah } & \multicolumn{2}{c|}{ Wyoming } \\
\hline Statistic & $\mathrm{d} \leq 600 \mathrm{~m}$ & $\mathrm{~d}>600 \mathrm{~m}$ & $\mathrm{~d} \leq 600 \mathrm{~m}$ & $\mathrm{~d}>600 \mathrm{~m}$ & $\mathrm{~d} \leq 600 \mathrm{~m}$ & $\mathrm{~d}>600 \mathrm{~m}$ \\
\hline Min & 15.62 & 14.33 & 29.79 & 7.29 & 6.26 & 50.17 \\
\hline Max & 109.56 & 58.61 & 207.60 & 201.02 & 903.35 & 1294.99 \\
\hline Range & 93.94 & 44.28 & 177.81 & 193.73 & 897.09 & 1244.82 \\
\hline Mean & 30.27 & 30.87 & 123.22 & 58.86 & 105.96 & 72.95 \\
\hline SD & 9.83 & 10.56 & 33.23 & 17.46 & 147.11 & 103.24 \\
\hline Variance & 96.64 & 111.43 & 1104.17 & 304.97 & 21642.70 & 10657.94 \\
\hline
\end{tabular}

Source: National Coal Resources Data System. NCRDS. Own elaboration by using Surfer $8^{\circ}$

Despite the previous statistical analysis and the histogram for all the raw data' construction, it is necessary to keep in mind, that each sample has its own spatial characteristics. It means that each sample was made by maintaining a rule concerning the Lag distance between the samples.
It is recommendable to know the Lags vector direction for each field; as it was explained in the previous sections. For example, let us observe the Colorado State sample's configuration, for a depth bigger than $600 \mathrm{~m}$ (see Fig. 3).

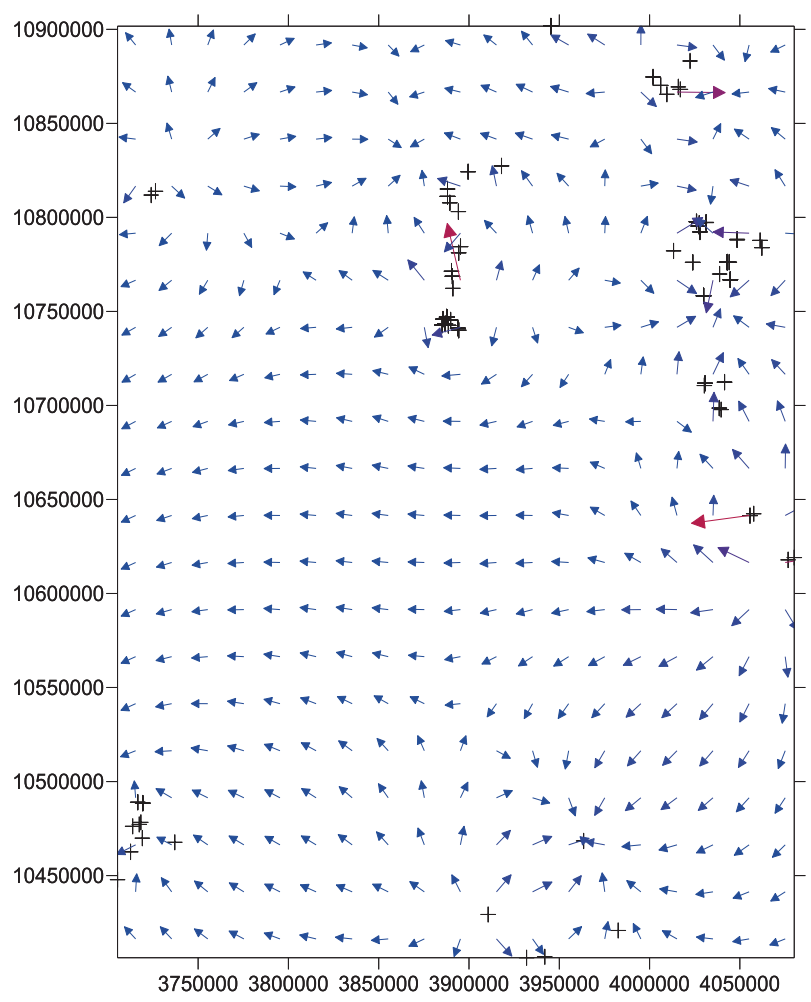

Fig. 3. Colorado Vector Map (Deeper than 600m; each blue arrow represents the direction of the Lags. Black plus symbols represents the drill holes in the field)

Source: National Coal Resources Data System. Own elaboration by using Surfer $8^{\circ}$ 
Analyzing the tables $1 \mathrm{a}$ and $1 \mathrm{~b}$, one can observe that, contrary to what was expected, there is not an absolute regularity between the results. In the cases of Colorado, Iowa, and in less extent, Ohio, the average coal seam thickness increases with the depth; and for the other States it decreases as expected. On the other hand, and for this article purpose, it is much more important the behavior found concerning the sample's spatial variance. Since it is assumed the anisotropy existence, the changes in the vertical direction are quicker than the horizontal ones. So, it could be expected than the deeper the resources exploitation, the greater the variance. However, it was just proved for Colorado, Iowa, North Dakota, and Ohio.

These findings do not imply that the resources increasing in spatial variance's condition, is false. Let us remind that this variogram has not been calculated across the multiple data. It just takes into account the coal seam thickness. For example, when the variogram is done for another variable, the results are different. In the Kentucky case, a run on Surfer $8^{\circ}$ was carried out for both subsets, with the variable 'Fixed Carbon'. The results were completely different (see Table 3 ).

TABLE 2

RESUlts OF THE VARIOGRAM WITH FIXED CARBON

\begin{tabular}{|l|c|c|}
\hline & \multicolumn{2}{|c|}{ Kentucky } \\
\hline Statistic & $\mathrm{d} \leq 600 \mathrm{~m}$ & $\mathrm{~d}>600 \mathrm{~m}$ \\
\hline Min & 36.83 & 34.30 \\
\hline Max & 53.05 & 55.62 \\
\hline Range & 16.22 & 21.32 \\
\hline Mean & 45.70 & 45.65 \\
\hline SD & 2.96 & 3.88 \\
\hline Variance & 8.76 & 15.09 \\
\hline
\end{tabular}

Source: NCRDS. Own elaboration by using Surfer $8^{\circ}$

This result is quite important as a justification for this work. A cross variogram could support the thesis, that exploiting coal deeper than it is possible with traditional mining, while it becomes riskier, at the same time increases the coal resources' recoverable amount.

It is important to clarify, that the next section regards the simulation based on this preliminary data and look for a comparison. However, the coal seams are not a continuum, then this inference based on a simulation, needs to be taken as an ideal scenario. In the same way, the data presented before is an input for a simulation model and has been used to calibrate the starting model's variables.

2) Simulated scenario: The simulated scenario's construction, was made by the Montecarlo Simulation program. All runs were calculated by the cross variogram and the Kriging variance. It was used a model with the nugget effect for a cross variogram, and for each individual variogram of: Thickness (Sampthk), moisture (Moistr), volatility or volatility matters (Volmat), fixed carbon (Fixedc), ash value (Stdash) and Sulfur contain (Slfur). No trend or Gaussian transformations were employed, given the data heterogeneity.

The variogram was modeled by using a simple Excel spreadsheet and by the definition given at Kelkar et al. [30], without any transformation or trend. An initial database was used in order to parameterize the model. It was selected the Ohio Sample, given the spatial statistical properties found in a former section. However, the sample was divided in two files, as the subsets described above, according with the sample's depth. In this case, it was used 3D Lags program, As in 
the geometric anisotropy's case, this analysis implies three dimensions, where $\vec{u}$ and $\vec{v}$ are the horizontal directions, and $\vec{w}$ the vertical one: $L_{D}=\sqrt{\left(\frac{\overrightarrow{L_{u}}}{a_{u}}\right)^{2}+\left(\frac{\overrightarrow{L_{v}}}{a_{v}}\right)^{2}+\left(\frac{\overrightarrow{L_{w}}}{a_{w}}\right)^{2}}$, for the variogram construction. The results are very intuitive when compared, since the variance is greater, when the sample is deeper than $600 \mathrm{~m}$. If the variograms are treated by any independent variables, the results are as expected (see Table 3).

\section{TABLE 3A}

VARIOGRAMS FOR A BASE MODEL UP TO 600M

\begin{tabular}{|c|c|c|c|c|c|}
\hline $\begin{array}{c}\text { Variance } \\
\text { term }\end{array}$ & varj(t) & varj(m) & varj(v) & varj(f) & varj(a) \\
\hline 1st term & 101,21305 & 1,67212293 & 8,71265541 & 12,7322182 & 24,1558417 \\
\hline 2nd term & 105,338125 & 1,68482147 & 9,22572115 & 13,048583 & 29,5596654 \\
\hline 3rd term & 104,996904 & 1,54352806 & 9,82515161 & 11,9484729 & 28,3413481 \\
\hline 4th term & 113,615934 & 1,3952237 & 9,59690487 & 13,1016851 & 30,7756133 \\
\hline 5th term & 113,902688 & 1,53161275 & 9,10348137 & 14,0954314 & 29,5391127 \\
\hline 6th term & 104,897936 & 1,47275658 & 8,73464408 & 12,3669648 & 26,0000474 \\
\hline 7th term & 107,591499 & 1,40107119 & 8,84492185 & 12,6376228 & 28,1825599 \\
\hline 8th term & 113,575967 & 1,574547 & 8,97497133 & 13,7011233 & 28,4655513 \\
\hline 9th term & 119,693901 & 1,63345738 & 7,67793557 & 13,0848732 & 28,0245329 \\
\hline 10th term & 100,151799 & 1,53319155 & 8,28064932 & 10,52755 & 25,640827 \\
\hline
\end{tabular}

Source: NCRDS. Own elaboration

TABLE3B

VARIOGRAMS FOR A BASE MODEL DEEPER THAN 600M

\begin{tabular}{|c|c|c|c|c|c|}
\hline $\begin{array}{c}\text { Variance } \\
\text { term }\end{array}$ & varj(t) & varj(m) & varj(v) & varj(f) & varj(a) \\
\hline 1st term & 246,4322476 & 1,684196429 & 10,68385833 & 10,18783929 & 32,092975 \\
\hline 2nd term & 208,2629732 & 2,140557317 & 10,88223537 & 8,99624878 & 32,67050732 \\
\hline 3rd term & 269,8012038 & 2,19311125 & 9,9232 & 11,78594 & 36,02982625 \\
\hline 4th term & 292,8780615 & 1,810657692 & 9,368894872 & 8,977105128 & 28,2173859 \\
\hline 5th term & 291,6453461 & 1,627703947 & 10,575725 & 11,72586447 & 29,18839868 \\
\hline 6th term & 259,6485311 & 2,230675676 & 11,54813784 & 12,22822027 & 39,53226081 \\
\hline 7th term & 298,5448931 & 2,177704167 & 8,506016667 & 11,36922639 & 27,791525 \\
\hline 8th term & 286,3160614 & 1,936365714 & 7,394331429 & 12,06679429 & 28,82992857 \\
\hline 9th term & 326,7237324 & 1,671695588 & 11,02185294 & 11,58761912 & 34,89043235 \\
\hline 10th term & 282,3698682 & 2,831581818 & 9,454730303 & 13,71468485 & 35,23459697 \\
\hline
\end{tabular}

Source: NCRDS. Own elaboration 
A cross variogram was carried out by relating the thickness and the moisture variables. The results were similar to the former simple variograms.

Then, once the preliminary hypotheses were assumed, the model was parameterized on a
Crystal Ball's computer program. All the main distributions variables were modeled according with the results shown in previous section. Some adjustment proves were carried out, in order to find the parameters better distribution (using the raw data) to fit well the model (see Table 4).

TABLE 4

ADJUSTMENT MODELS FOR RAW DATA DEEPER THAN 600M

\begin{tabular}{|c|c|c|c|c|c|}
\hline Data & Thickness & Moisture & Volatility & Fixed C & Ash \\
\hline Distribution & 35,25 & 2,8 & 38,02 & 43,99 & 15,18 \\
\hline Better adjustment & Logistic & Lognormal & Beta & Beta & Gamma \\
\hline Anderson-Darling & 0,3995 & 0,7488 & 0,2065 & 0,1714 & 0,4209 \\
\hline P Value & 0,297 & 0,020 & --- & --- & 0,260 \\
\hline
\end{tabular}

Source: NCRDS; Own elaboration by Oracle Crystall Ball.

After adjustments, 10.000 runs were simulated and the sample thickness showed a decrease, when is taken deeper than $600 \mathrm{~m}$, as expected. When simulated as thickness having a lognormal distribution, the first term variance (zero difference) becomes greater. The most interesting finding is the changes assumed in the raw data distribution, when the samples are taken up to 600m (See Table 5).

\section{TABLE 5}

AdJUSTMENT MODELS FOR THE RAW DATA UP TO 600 M.

\begin{tabular}{|c|c|c|c|c|c|}
\hline Data & Thickness & Moisture & Volatility & Fixed C & Ash \\
\hline Distribution & 35,87 & 4,04 & 38,59 & 42,93 & 14,18 \\
\hline Betteradjustment & Maximum Extreme & Beta & Weibull & Weibull & Lognormal \\
\hline Anderson-Darling & 0,5369 & 0,1547 & 0,3881 & 0,1426 & 0,1646 \\
\hline P Value & 0,172 & --- & 0,223 & 0,954 & 0,906 \\
\hline
\end{tabular}

Source: NCRDS; Own elaboration by Oracle Crystall Ball.

The results indicate that the thickness decreases a small amount, which implies that there is a probability to find a coal reserves considerable amount. This fact is discussed in a more detailed way in the next sub-section.

On the other hand, the resources have different distribution when exploitation goes deeper by using different technology. It could be explained possibly due to the zonal anisotropy, which is faster when the direction is vertical, as was pointed out above. This increasing tendency implies not only the possibility to get more recoverable resources, but a riskier activity due to the growing uncertainty. So, it is clear that a deeper exploitation bring new economic opportunities, but it requires to assume more risk, which is costly as well. 


\section{About theoretical increasing in the volume of coal reserves}

Whatever be the assumption about the coal reserves distribution, it is a fact that the any technology development, which changes the coal exploitation conditions, must change the reserves definitions with a certain probability.

As all previous research indicates [10] it is important to keep in mind, that this incremental is not absolute. A $65 \%$ recoverable factor has been applied to UCG projects, under some constraints like thickness or bituminous. Additionally, as it was explained before, the necessity to avoid any water contamination obligates to leave unexploited the coal seam walls.

In terms of resources availability to be exploited, it is considered that $600 \mathrm{~m}$ is the border where coal exploitation is economically viable. If UCG technology allows a deeper resources recovering, to $1200 \mathrm{~m}$ or $1500 \mathrm{~m}$, it could represent at least a $100 \%$, increase in the reserves recovery with a certain probability level, given the associated reserves calculation.

However, as in the Montecarlo simulation's case, is just one specific way to claim for this increment. It would be necessary to calculate the reserves amount with a new definition, under the UCG technology implementation, by using a standard procedure as described in Section 4.

However, some authors like Burton et al. [8] consider that under UCG technology, reserves can increase around $300 \%$ to $400 \%$. Despite those considerations, it is possible to increase the uncertainty as well.

\section{Conclusions and Remarks}

The UCG technology development has imposed a new engineering and environmental challenges related to its implementation. There are a considerable number of studies, concerning this kind of projects technical issues and evaluations.

Also, several economic evaluations can be found in this area. In despite of being recognized as an advantage that this technology allows to recover resources considered unrecoverable by traditional mining, this aspect has not been sufficiently considered yet.

One of the UCG implementation consequences is the accessibility to the coal resources at depths greater than $600 \mathrm{~m}$, which is considered the border for the economically viable traditional mining. Such a new resources finding implies an incremental in the recoverable coal resources inventory. From this point of view, any UCG project viability, redefines the recoverable resource concept.

However, it is necessary to be cautious with any easy consideration about that increase in the recoverable resources. As it has been shown, due to technical issues like the anisotropy, to go deeper implies more uncertainty in the resources calculation. As the interest in UCG increases by one hand, in the other, that uncertainty could be a constraint in an environment development, where investors are risk averse. One of the main subjects related to the uncertainty, is the underground fire control, where it is almost impossible to have any certainty; however, some studies have reached important advances in this matter [39], [40].

Then it is necessary to obtain the real data, in order to evaluate more closely and with confidence, any UCG project in Colombia. If INGEOMINAS would have control points on hypothetical reserves proposed for depths greater than 600 $\mathrm{m}$ [24], this inventory could be translated to the proven reserves in the country.

This paper calls out the researchers and investors' attention, especially those who are in charge of these projects' economic and financial evaluations, to consider the issues pointed out here. 


\section{AKNOWLEDMENTS}

Author wants to acknowledge to Engineer Luis C. Mojica from INGEOMINAS; to Engineer Andres David Díaz Jaramillo for his comments; and, the two blind reviewers.

\section{REFERENCES}

[1] J. Herrera, "Estimación de la producción minera colombiana por distritos, basada en proyecciones del PIB minero Latinoamericano 2008-2019," presented at the Colombia minera: desarrollo responsable, Bogotá, 01-Aug-2008.

[2] WCI, "El carbón como recurso, una visión general del carbón," World Coal Institute, United Kingdom, Informe Técnico, 2005.

[3] World Coal Association, "Coal statistics." [Online]. Available: http://www.worldcoal. org/resources/coal-statistics/.

[4] M. Barrientos and C. Soria, "Index Mundi," World coal comsumption by year. [Online]. Available: http:// www.index mundi.com/ energy. aspx? product $=$ coal\&graph $=$ consumption .

[5] U.S. Energy Information Administration, "International Energy Statistics," EIA. [Online]. Available: http://www.eia. gov/cfapps/ipdbproject/IEDIndex 3 . cfm?tid=1\&pid=1\&aid=2.

[6] S. J. Friedmann, R. Upadhye, and F. M. Kong, "Prospects for underground coal gasification in carbon-constrained world," Energy Procedia, vol. 1, no. 1, pp. 45514557, 2009.

[7] E. Shafirovich and A. Varma, "Underground coal gasification: a brief review of current status," Industrial \& Engineering Chemistry
Research, vol. 48, no. 17, pp. 7865-7875, 2009.

[8] E. Burton, J. Friedmann, and R. Upadhye, "Best practices in underground coal gasification," Contract No. W-7405-Eng-48, Lawrence Livermore National Laboratory, Livermore, CA, 2006.

[9] A. Y. Klimenko, "Early Ideas in Underground Coal Gasification and Their Evolution," Energies, vol. 2, pp. 456-476, Jun. 2009.

[10] D. A. Bell and B. F. Towler, Coal gasification and its applications. William Andrew Pub, 2010.

[11] J. Verdon, "Underground Coal Gasification" Frack-Land Blog; http://frackland. blogspot.com/2012/01/underground-coalgasification.html

[12] A. Ad Mohamed, et al., "Viability of Underground Coal Gasification with carbon capture and storage in Indiana." 04-May2011.

[13] M. Mastalerz, D. Agniezka, M. Parke, and J. Rupp, "Site Evaluation of Subsidence Risk, Hydrology, and Characterization of Indiana Coals for Underground Coal Gasification," Center for Coal Technology Research (CCTR), Indiana State Agency, Purdue University, Technical report, Mar. 2011.

[14] Green America, "Carbon sequestration," Climate and Energy. Economic action to stop global warming. [Online]. Available: http://www.greenamerica.org/programs/ climate/dirtyenergy/coal/ccs.cfm.

[15] M. N. Heriawan and K. Koike, "Identifying spatial heterogeneity of coal resource quality in a multilayer coal deposit by 
multivariate geostatistics," International Journal of Coal Geology, vol. 73, no. 3-4, pp. 307-330, 2008.

[16] M. Álvarez-Fernández， C. GonzálezNicieza, A. Álvarez-Vigil, G. Herrera García, and S. Torno, "Numerical modelling and analysis of the influence of local variation in the thickness of a coal seam on surrounding stresses: Application to a practical case," International Journal of Coal Geology, vol. 79, no. 4, pp. 157-166, 2009.

[17] M. Sivek, M. Cáslavsk1, and J. Jirásek, "Applicability of Hilt's law to the Czech part of the Upper Silesian Coal Basin (Czech Republic)," International Journal of Coal Geology, vol. 73, no. 2, pp. 185195, 2008.

[18] M. Sivek, J. Jirásek, L. Sedlácková, and M. Cáslavsk1, "Variation of moisture content of the bituminous coals with depth: A case study from the Czech part of the Upper Silesian Coal Basin," International Journal of Coal Geology, vol. 84, no. 1, pp. 16-24, 2010.

[19] Ecocarbon, "Normas generales sobre muestreo y análisis de carbones." Ministerio de Minas y Energía, 1995.

[20] R. Sabourin, "Geostatistics as a tool to define various categories of resources," Mathematical Geology, vol. 15, no. 1, pp. 131-143, 1983.

[21] B. Alpern and M. Lemos de Sousa, "Documented international enquiry on solid sedimentary fossil fuels; coal: definitions, classifications, reserves-resources, and energy potential," International journal of coal geology, vol. 50, no. 1-4, pp. 3-41, 2002.
[22] J. H. Schuenemeyer and H. C. Power, "Uncertainty estimation for resource assessment - an application to coal," Mathematical Geology, vol. 32, no. 5, pp. 521-541, 2000.

[23] G. Bardossy, I. Szabo, and G. Varga, "A new method of resource estimation for bauxite and other solid mineral deposits," BERG UND HUTTENMANNISCHE MONATSHEFTE, vol. 148 , no. 2, pp. 57 64, 2003.

[24] L. Luna, E. Rodríguez, C. Sánchez, G. Renzoni, E. Hernández, J. Maldonado, C. Alba, and A. Sanabria, El carbón colombiano: recursos, reservas y calidad. Bogotá: Ministerio de Minas y Energía, Instituto Colombiano de Geología y Minería, 2004.

[25] R. L. Oliver and G. F. Dana, "Underground coal gasification," DC Peters (Rd.) Geology in Coal Resource Utilization. Energy Minerals Division, AAPG. TechBooks, Fairfax, 1991.

[26] R. Caldwell and D. Heather, "How to evaluate hard-to-evaluate reserves," Journal of Petroleum Technology, vol. 43, no. 8, pp. 998-1003, 1991.

[27] W. Phillips, "Statistical estimation of global mineral resources," Resources Policy, vol. 3, no. 4, pp. 268-280, 1977.

[28] B. A. Bancroft and G. R. Hobbs, "Distribution of kriging error and stationarity of the variogram in a coal property," Mathematical geology, vol. 18, no. 7, pp. 635-652, 1986.

[29] M. E. Hohn, Geostatistics and petroleum geology. Springer, 1999. 
[30] M. Kelkar, G. Perez, and A. Chopra, Applied geostatistics for reservoir characterization. Society of Petroleum Engineering, 2002.

[31] S. Li, R. Dimitrakopoulos, J. Scott, and D. Dunn, "Quantification of geological uncertainty and risk using stochastic simulation and applications in the coal mining industry," Orebody Modelling and Strategic Mining Planning: The Australasian Institute of Mining and Metalurgy, Melbourne, pp. 233-240, 2004.

[32] M. Zare, F. Sereshki, and N. Aziz, "Application of Financial Risk Analysis for Project Evaluation at a Large Coal Mine," in Coal Operators' Conference, 2008, p. 29.

[33] J. Costa, A. Zingano, and J. Koppe, "Simulation: An Approach to Risk Analysis in Coal Mining," Exploration and Mining Geology, vol. 9, no. 1, pp. 43 -49, Jan. 2000.

[34] X. Emery, "Conditioning simulations of Gaussian random fields by ordinary kriging," Mathematical Geology, vol. 39, no. 6, pp. 607-623, 2007.

[35] K. Saikia, B. C. Sarkar, and P. M. Sinha, "Application of kriging and simulated annealing for spatial variability modelling of a coal seam," Applied Earth Science:
Transactions of the Institution of Mining \& Metallurgy, Section B, vol. 116, no. 1, pp. 37-48, Mar. 2007.

[36] J. D. Sterman and G. P. Richardson, "An experiment to evaluate methods for estimating fossil fuel resources," Journal of forecasting, vol. 4, no. 2, pp. 197-226, 1985.

[37] Coalfiedls Geology Council of NSW, "Guidelines for the Estimation and Reporting of Australian Black Coal Resources and Reserves." Queensland Mining Council, 2001.

[38] USGS, "Energy resources program: coal quality," U. S. Geological Survey. [Online]. Available: http://energy.usgs.gov/Coal/ AssessmentsandData/CoalQuality.aspx.

[39] A. Prakash and Z. Vekerdy, "Design and implementation of a dedicated prototype GIS for coal fire investigations in North China," International journal of coal geology, vol. 59, no. 1-2, pp. 107-119, 2004.

[40] J. Wu and X. Liu, "Risk assessment of underground coal fire development at regional scale," International Journal of Coal Geology, 2010. 